\title{
Submicroscopic aberrations of chromosome 16 in prenatal diagnosis
}

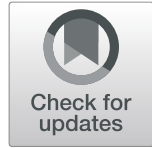

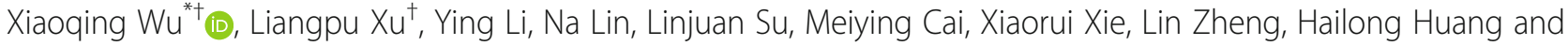 \\ Yuan Lin
}

\begin{abstract}
Background: Nearly $9.89 \%$ of chromosome 16 consists of segmental duplications, which makes it prone to nonhomologous recombination. The present study aimed to investigate the incidence and perinatal characteristics of submicroscopic chromosome 16 aberrations in prenatal diagnosis.

Results: A total of 2,414 consecutive fetuses that underwent prenatal chromosomal microarray analysis (CMA) between January 2016 and December 2018 were reviewed. Submicroscopic anomalies of chromosome 16 accounted for $11.1 \%(15 / 134)$ of all submicroscopic anomalies detected in fetuses with normal karyotype, which was larger than the percentage of anomalies in any other chromosome. The 15 submicroscopic anomalies of chromosome 16 were identified in 14 cases; 12 of them had ultrasound abnormalities. They were classified as pathogenic $(N=7)$, and variants of uncertain significance $(N=8)$. Seven fetuses with variants of uncertain significance were ended in live-born, and the remaining were end in pregnancy termination.

Conclusion: Submicroscopic aberrations of chromosome 16 are frequent findings in prenatal diagnosis, which emphasize the challenge of genetic counseling and the value of CMA. Prenatal diagnosis should lead to long-term monitoring of children with such chromosomal abnormalities for better understanding of the phenotype of chromosome 16 microdeletion and microduplication syndromes.
\end{abstract}

Keywords: Submicroscopic aberrations, Chromosome 16, Chromosomal microarray analysis, Prenatal diagnosis

\section{Background}

It is well known that complete trisomy 16 is embryonic lethal, and it is the most common autosomal anomaly revealed by genetic diagnosis of spontaneous miscarriage [1]. Human chromosome 16 has one of the highest levels of segmental duplication: nearly $9 \%$ of genome-wide human duplication alignments map to this chromosome. Nearly $9.89 \%(7.8 \mathrm{Mb})$ of chromosome 16 consists of segmental duplications in the form of low copy repeats (LCRs) [2]. LCR16a, a $20 \mathrm{~Kb}$ low-copy repeat sequence, is the most frequent chromosome-specific duplication distributed in multiple locations over the entire length of chromosome 16 in a non-tandem manner. Most of it is concentrated on the short arm, including cytogenetic band locations 16p13.3,

\footnotetext{
* Correspondence: wuxiaoging013@126.com

${ }^{+}$Xiaoqing Wu and Liangpu Xu contributed equally to this work

Fujian Key Laboratory for Prenatal Diagnosis and Birth Defect, Fujian

Provincial Maternity and Children's Hospital, affiliated Hospital of Fujian

Medical University, No.18 Daoshan Road, Gulou District, Fuzhou 350001 China
}

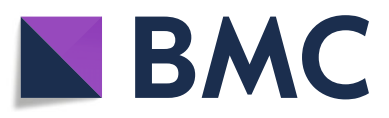

(c) The Author(s). 2019 Open Access This article is distributed under the terms of the Creative Commons Attribution 4.0 International License (http://creativecommons.org/licenses/by/4.0/), which permits unrestricted use, distribution, and

reproduction in any medium, provided you give appropriate credit to the original author(s) and the source, provide a link to the Creative Commons license, and indicate if changes were made. The Creative Commons Public Domain Dedication waiver (http://creativecommons.org/publicdomain/zero/1.0/) applies to the data made available in this article, unless otherwise stated. This duplication may potentially lead to the rearrangement of the short arm segments of chromosome 16, which explains the high variability in breakpoints and sizes of $16 \mathrm{p}$ microdeletions and micro-duplications.

Although the segmental repeats are enriched in the relatively gene-poor pericentromere of the short arm, some are likely to have an impact on human disease susceptibility [2]. Several loci associated with chromosome 16 have been frequently examined in conjunction with susceptibility to disorders of the nervous system. In some studies concerning the utility of the chromosomal microarray analysis (CMA) in prenatal testing, microduplications or microdeletions associated with chromosome 16 were relatively frequent findings $[4,5]$. To the best of our knowledge, rare studies have systematically described the prenatal diagnosis due to the limitations of phenotypic identification in prenatal practice. Here, we investigated the frequency of the microdeletions and microduplications associated with chromosome 16 in 2,414 fetuses who underwent prenatal 
CMA for different indications. Our data emphasize the value of CMA in prenatal diagnosis and the importance of long-term postnatal follow-up for fetuses with likely pathogenic aberrations.

\section{Results}

A total of 134 submicroscopic aberrations were identified in $117(4.8 \%, 117 / 2,414)$ fetuses with normal karyotype or balanced structural aberration, including 51 cases of copy gain, 66 cases of copy loss, and 17 cases of loss of heterozygosity (LOH). Aberrations derived from chromosome 16, $11.1 \%$ (15/134), were observed with the highest frequency, followed by those of chromosome 2 and 22 (Fig. 1). Copy number variants $(\mathrm{CNVs})$ of chromosome 16 ranged from $600 \mathrm{~kb}$ to $2.24 \mathrm{Mb}$ in size (Table 1 ).

Cases 1-6 harbored CNVs of different size in chromosome locus 16p13.11. Cases 1 and 2 (boy infants) both showed a $1.25 \mathrm{Mb}$ duplication in the same region of $16 \mathrm{p} 13.11$ and had normal phenotype during the followup. Case 1 inherited $827 \mathrm{~kb}$ of the $1.25 \mathrm{Mb}$ deletion from a healthy father, with the additional repeat segment encompassing NTAN1 (OMIM \# 615367), a candidate schizophrenia gene. Ultrasonography in both cases showed abnormalities of soft markers: bilateral lateral ventricle dilatation for Case 1, echogenic bowel and mild tricuspid regurgitation for Case 2. Case 3 harbored a maternally inherited 1.1-Mb duplication. The mother had normal phenotype. The fetus showed ultrasound soft marker abnormality and was delivered at $37^{+4}$ weeks with a birth weight of $2.4 \mathrm{~kg}$. However, at the follow-up after 12 months, the weight was $4.4 \mathrm{~kg}$, which indicated physical retardation. In Case 4, a 947-kb duplication in the region of 16p13.11 was present in a fetus with Urorectal Septum Malformation Sequence (URSMS). Microduplications of $16 \mathrm{p} 13.11$ usually have incomplete penetrance and/or variable expression. They mainly manifest as cognitive impairment, behavioral disorders, congenital heart defects, and skeletal malformations, thus that CNV may not have been the reason for URSMS. In Case 5, a de novo 796-kb duplication in 16p13.11 was found in a fetus with normal ultrasound data. The infant showed normal development during 14-month follow-up. In the current study, we reported the hereditary 16p13.11 duplication as "likely benign". In contrast with the five above cases, Case 6 harbored $a$ de novo 1.0-Mb deletion in 16p13.11 region, associated with the 16p13.11 microdeletion syndrome. The fetus manifested with echogenic bowel and progressive bilateral ventriculomegaly, which could be caused by the CNVs. We classified it as a pathogenic variants and the parents opted for the termination of the pregnancy.

Four cases of de novo CNVs (Cases 7-10) represented the known clinical 16q11.2 microdeletion syndrome (OMIM \#611913). They all had a $\sim 600 \mathrm{~kb}$ deletion encompassing the critical region of a typical

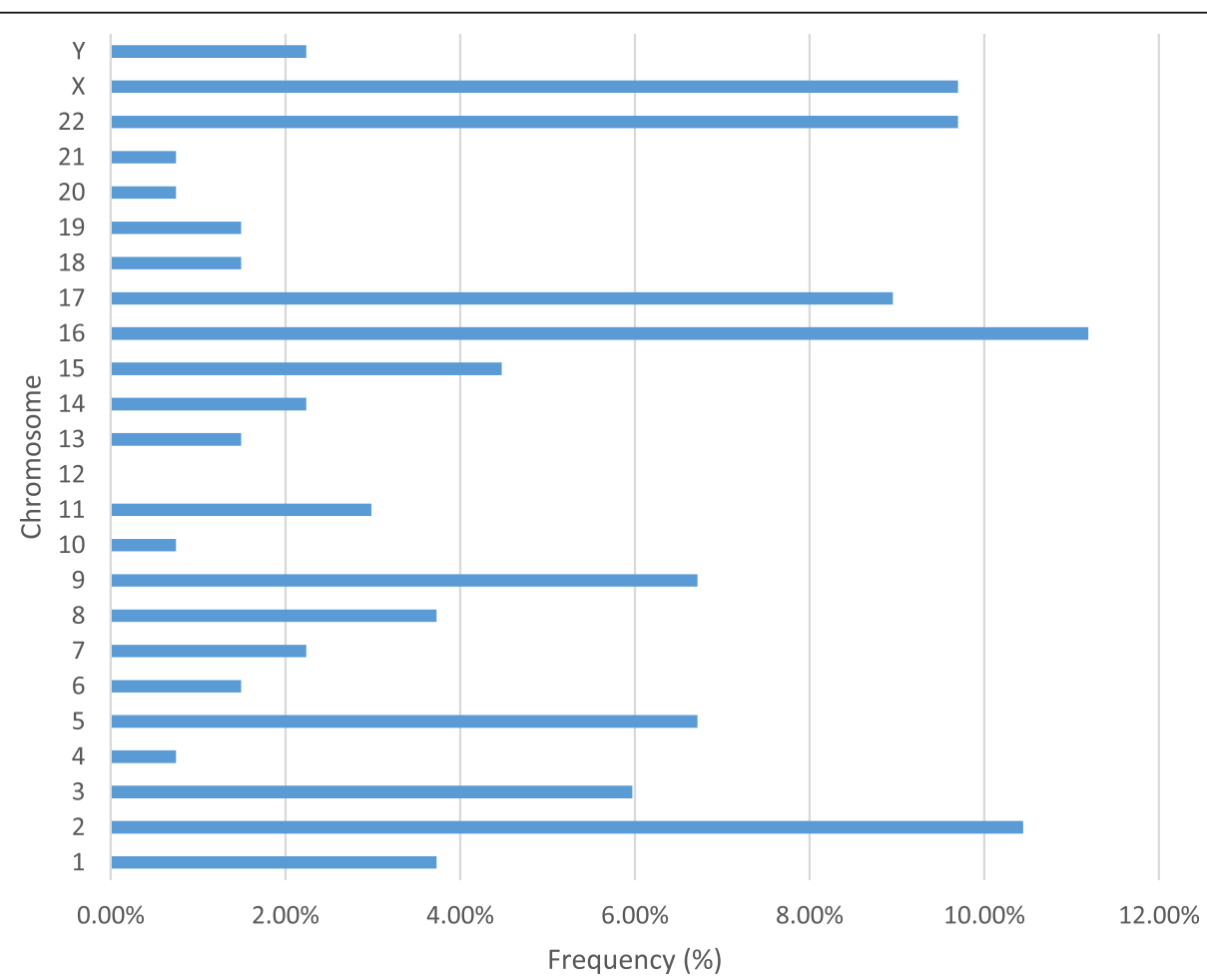

Fig. 1 The frequency of 134 submicroscopic anomalies on each chromosome. All chromosomes except for chromosome 12 were involved. Among them, 11.1\% (15/134) aberration derived from chromosome 16, which had the highest frequency, followed by chromosome 2,22 and $X$ 


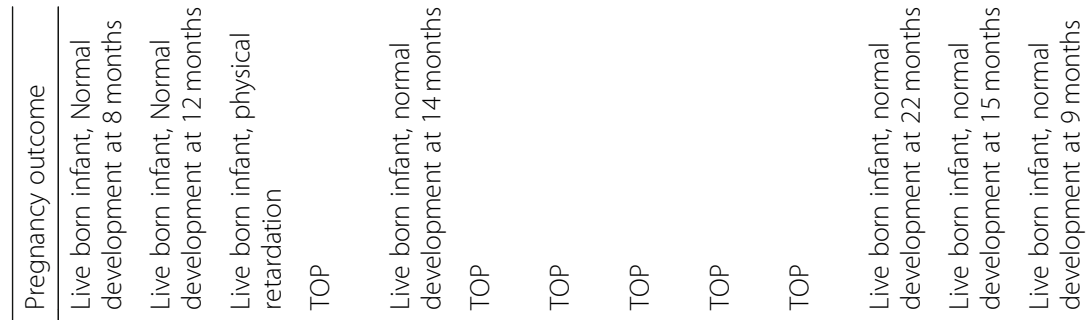

ڤे

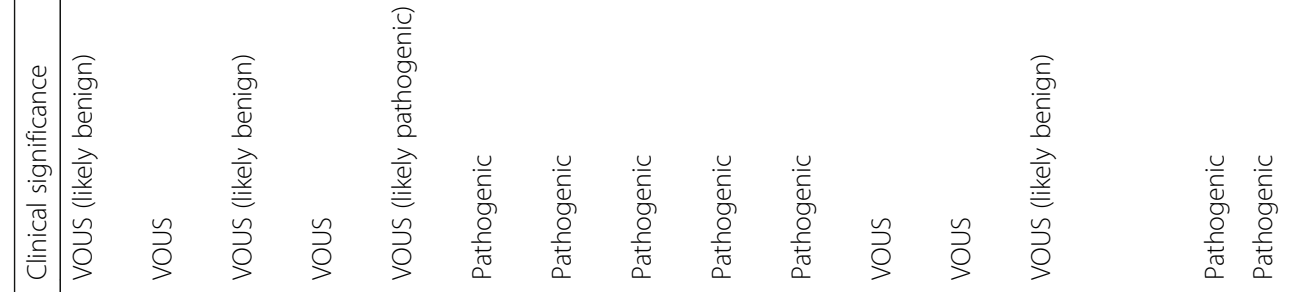

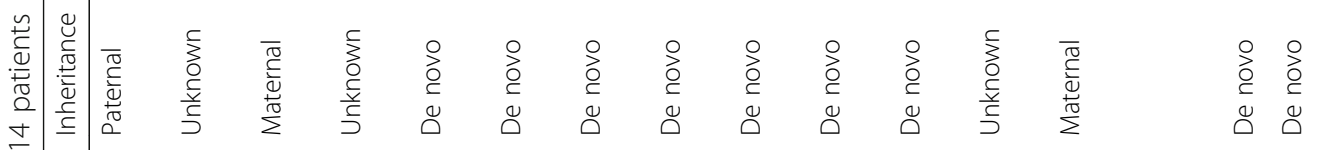

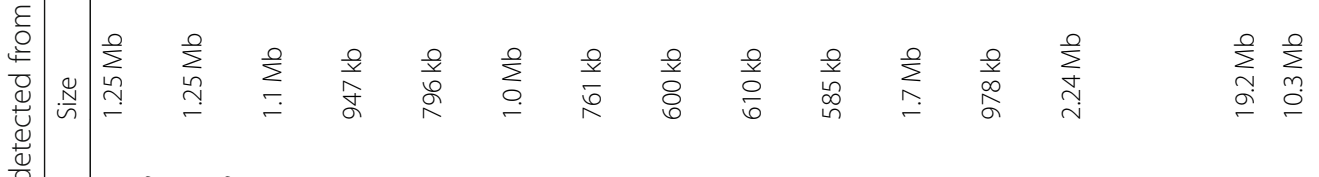


16q11.2 microdeletion syndrome. Two fetuses showed congenital malformations involving the spine (Cases 7 and 9), whereas Cases 8 and 10 showed brain abnormalities. These pregnancies were terminated after counseling. Case 11 showed a de novo $1.7-\mathrm{Mb}$ duplication in region 16p11.2, which was classified as variants of uncertain significance (VOUS) as it involved no OMIM genes and was not found in public CNV databases. Considering that there was only a single soft marker abnormality, the fetus had termed birth.

Case 12 had a 978-kb deletion in region 16q12.2, containing four OMIM genes: OTOA (607038), UQCRC2 (191329), EEF2K (606968), CDR2 (117340). This deletion was reported as benign in DGV, but some cases with pathologies were described in DECIPHER. In addition, the deleted segment partly overlapped with the 16p11.2-12.2 deletion syndrome region, and it also contained a microdeletion of a susceptibility site for a neurodevelopmental disorder. The inheritance mode was unclear as the parents declined the analysis of their samples. Thus it was interpreted as "VOUS", more likely pathogenic. Finally, an infant with normal phenotype was delivered and had normal development during 15 months of the follow-up. Case 13 harbored a 2.24-Mb deletion in region 16q23.3q24.1, involving 14 OMIM genes. Parental testing revealed maternal inheritance from healthy mother. Case 14 revealed two copies of neutral $\mathrm{LOH}$ of $19.2 \mathrm{Mb}$ and $10.3 \mathrm{Mb}$ in $16 \mathrm{p} 13.3 \mathrm{p} 12.3$ and $16 \mathrm{q} 23.2 \mathrm{q} 24.3$ regions, respectively (Fig. 2). A maternal isodisomic uniparental disomy (iUPD) was confirmed after trio analysis with the UPD tool.

\section{Discussion}

The presence of segmental duplications or LCRs on chromosomes facilitates the occurrence of non-allelic homologous recombination during meiosis. It may result in microduplications and microdeletions [6,7]. This is particularly evident in human chromosome 16 , microduplications and microdeletions of which cause serious clinical syndromes. Here, we described 14 fetuses with segmental rearrangements mainly representing $16 \mathrm{p} 11.2$ microdeletion syndrome, $16 \mathrm{p} 11.2-\mathrm{p} 12.2$ microdeletion syndrome, 16p13.11 microdeletion syndrome, or 16p13.11 microduplication syndrome. It must pointed out that submicroscopic aberrations associated with chromosome 16 were most frequent of all submicroscopic aberrations detected in the present study, consistent with the results obtained by Cheng et al [8]. In some other studies, aberrations of chromosome 22 or $\mathrm{X}$ chromosome were more frequent than those of chromosome 16 . Nonetheless, the frequency of submicroscopic changes associated with chromosome 16 is still relatively high $[4,5]$.

The 16 p13.11 region contains nearly 14 known proteincoding genes. Unbalanced structural variation, deletions, and duplications occur most frequently in the short arm [9]. NDE1 (nudE nuclear distribution gene E homolog 1) and NTAN1 (N-terminal asparagine amidase) are the two genes that may be relevant to the neurocognitive phenotype. Loss or mutation of these genes has resulted in neurological manifestations in animal models, but the phenotypic consequences of gain are not that clear $[10,11]$. Microdeletions of 16p13.11 have been associated with multiple phenotypic manifestations, including neurodevelopmental phenotypes such as autism, epilepsy, and non-CNS

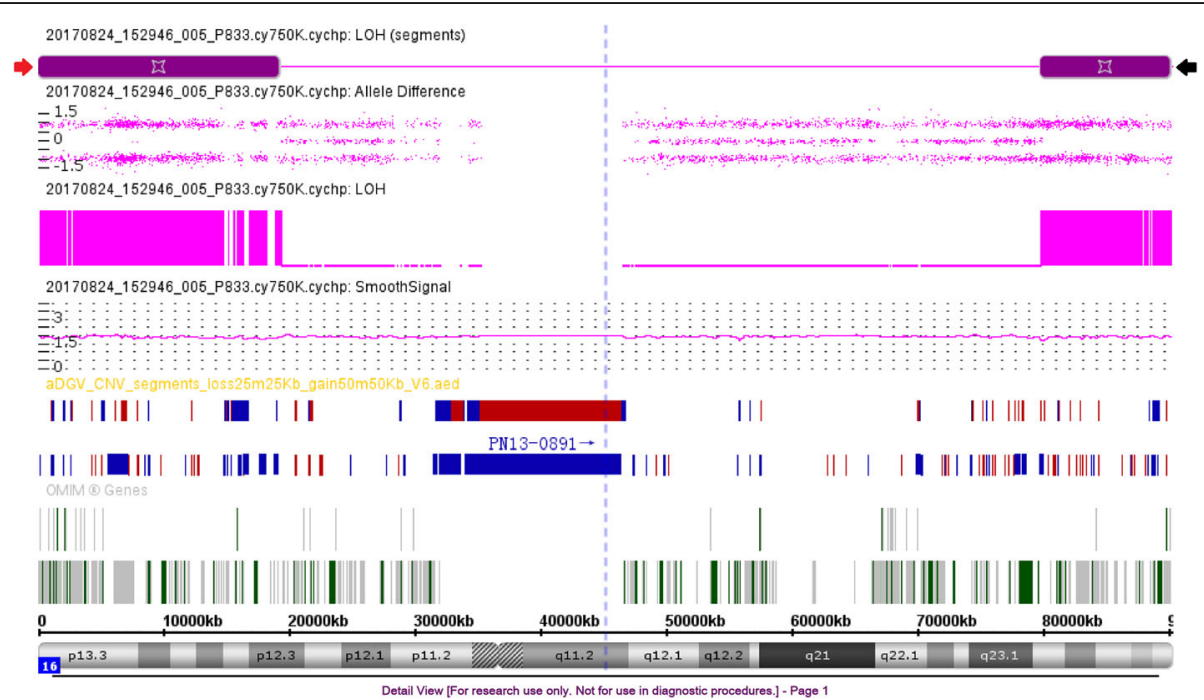

Fig. 2 SNP array results for the individual of UPD(16). SNP array analysis revealed two copies of neutral LOH of 19.2 Mb in 16p13.3p12.3 (red arrow) and $10.3 \mathrm{Mb}$ in 16q23.2q24.3 (black arrow) regions, respectively 
phenotypes, such as physical dysmorphisms and other congenital anomalies [12-15]. Evidence has accumulated that 16p13.11 microduplication may be associated with autism, schizophrenia, epilepsy, and attention-deficit hyperactivity disorder [15-17]. However, both types of aberrations were also detected in individuals with normal phenotype [11, 15]. This was interpreted by limited follow-up time. In our cohort, CNVs of 16p13.11 were most frequent (6/14). Five cases of 16p13.11 duplication were detected in fetuses with minor ultrasound abnormalities $(N=3)$, no ultrasound abnormalities $(N=1)$, and a fetus with Urorectal Septum Malformation Sequence $(N=1)$, with the latter case ending in the termination of pregnancy. Only one live born showed abnormal phenotype: physical retardation and speech delay during 14month follow-up. Notably, the duplication in this case was inherited from a heathy mother. The lack of a phenotype in the mother may be attributed to incomplete penetrance that was reported in $10.6 \%$ of mutations associated with developmental delay [18].

16p11.2 microdeletion syndrome was first proposed as a risk factor for autism spectrum disorder in 2008, with a population prevalence of approximately $0.03 \%$ [19-21]. The phenotypic spectrum includes autism, developmental retardation, mental retardation, spinal deformity, and a range of neuropsychiatric developmental diseases. The phenotypic features vary according to the size and location of the deletion. In the present study, four cases of $16 \mathrm{p} 11.2$ microdeletion were all located in the $29 \mathrm{M}-30.2 \mathrm{Mb}$ region and belonged to Group 1 [22], which is the most common type, involving HIRIP3, SEZ6L2, TBX6, and other genes [23, 24]. Insufficient expression of SEZ6L2 may be an important factor leading to speech delay and autism [25]. Mice homozygous for the loss-of-function mutation of $T b x 6$ show irregular phenotypes, such as rib fusion, spine fusion, and vertebral body fusion, indicating that insufficient expression of TBX6 in individuals with 16 p11.2 microdeletion is likely responsible for spinal deformity [26, 27]. Studies have reported that the polymorphism of the TBX6 gene is associated with hemivertebra and scoliosis in the Chinese Han population [28]; two in four cases in our study showed hemivertebra, consistent with the phenotype.

Ballif et al. established the identity of 16p11.2-p12.2 microdeletion syndrome by analyzing individuals with mental retardation, developmental delay, and common dysmorphic features [29]. It has a major difference from the 16p11.2 microdeletion syndrome, as it generally does not cause autism [30]. So far, almost all the patients share the same proximal breakpoint $21.4 \mathrm{Mb}$ and the distal break point is within $\sim 28.5$ $\mathrm{Mb}$ and $\sim 30.1 \mathrm{Mb}$. Here, Case 12 had just a $978-\mathrm{Kb}$ fragment overlapping with the 16p11.2-p12.2 microdeletion region, involving four OMIM genes, among them OTOA (607038) which is associated with hearing impairment, so it was classified as likely pathogenic.

UPD occurs when both members of a particular chromosome pair derive from the same parent and there is no contribution from the other parent. Case 14 was identified to have maternal $\operatorname{iUPD}(16)$, with the regions similar to those reported by Xie Yingjun et al. in a fetus with Fetal Growth Restriction (FGR). Case 14 fetus presented with FGR, congenital heart defect, and congenital renal dysplasia. UPD may cause clinical abnormalities through some common genetic mechanisms, including autosomal recessive disease, mosaicism, and imprinting. The regions of heterozygosity involved two genes associated with autosomal-recessive diseases, $C D T 1$, located at 16q24.3, and ALG1, located at 16p13.3 [31, 32]. However, these genes are unlikely to be the causes of FGR. Seven imprinted genes, SOX8, ZNF597, NAA60, SALL1, C16orf57, $A C D$, and $F O X F 1$, have been identified on chromosome 16 . Among them, ZNF597 located in 16p13.3 is expressed in the brain, leucocytes, and placenta [33]. It is maternally expressed, and its excessive expression in UPD(16) mat patients may affect placental development and cause growth failure [34, 35]. Thus, imprinting is a reasonable explanation for disease pathogenesis here.

There are many loci of susceptibility to neurodevelopmental disorders in chromosome 16 characterized by variable expression level and heterogeneity of clinical features [36]. Most fetuses do not have specific ultrasound findings in the uterus and often manifest only abnormal ultrasound soft markers. In such cases, a long period of follow-up is required for better prognosis; therefore, revealing information about these CNVs may be somewhat controversial. Most often, we reported such CNVs as "likely pathogenic". In the current study, the majority of "likely pathogenic" cases had normal development, which confirmed that phenotypic consequences of many CNVs for the fetus are always uncertain and that insufficiently long follow-up may not predict the phenotype accurately.

\section{Conclusions}

Submicroscopic aberrations on chromosome 16 are frequent findings, which emphasize the importance of CMA in prenatal diagnosis. These aberrations are mainly associated with the susceptibility to central nervous system disorders, and as they rarely cause specific ultrasound abnormalities, the long-term follow-up is needed to establish their pathogenicity. Prenatal diagnosis helps to ensure long-term followup of such children, which is critical for better understanding of the syndromic phenotypes of chromosome 16 microdeletion and microduplications. 


\section{Materials and methods}

\section{Patients and samples}

This retrospective study reviewed 2414 consecutive patients who underwent invasive prenatal diagnostic testing between January 2016 and October 2018 at the prenatal diagnosis center of Fujian Maternal and Child Health Hospital, affiliated hospital of Fujian Medical University, China. The mean maternal age ranging from 17 to 47 years, and gestational age ranging from 13 to 33 weeks. The samples comprised specimens of chorionic villus $(n=25)$, amniotic fluid $(n=1,819)$, and fetal cord blood $(n=570)$. The referral indications included advanced maternal age, abnormal trimester screening, abnormal pregnancy history, ultrasound abnormality. The study was approved by the local Ethics Committee of the Fujian Maternal and Child Health Hospital. Genetic counseling was provided to the patients before prenatal testing and written informed consent was obtained from all of them.

\section{CMA platforms and data interpretation}

CMA was performed with an Affymetrix CytoScan 750 $\mathrm{K}$ array (Affymetrix Inc., Santa Clara, CA, USA), which includes 200,000 probes for single nucleotide polymorphisms and 550,000 probes for copy number variations (CNVs) distributed across the entire human genome. The resolution for CNVs was $\geq 200 \mathrm{~kb}$ for deletions, $\geq 500 \mathrm{~kb}$ for duplications, and $\geq 10 \mathrm{Mb}$ for the loss of heterozygosity $(\mathrm{LOH})$. To analyze the results, Chromosome Analysis Suite software (Affymetrix) and human genome version GRCh37 (hg19) were used. All detected CNVs were compared with those listed in the following publically available databases: Database of Genomic Variants (DGV), Database of Chromosome Imbalance and Phenotype in Humans Using Ensemble Resources (DECIPHER), International Standards for Cytogenomic Arrays Consortium, and Online Mendelian Inheritance in Man (OMIM). Uniparental disomy (UPD) was reported based on the identification of the region of homozygosity $(\mathrm{ROH})$ covering the entire chromosome (complete isodisomic uniparental disomy, complete iUPD), a single large $(20 \mathrm{Mb})$ or multiple segments of $\mathrm{ROH}$ on a single chromosome (segmental iUPD). The family microarray data were processed to confirm maternal or paternal iUPD origin. They were classified using the UPD tool available at the following link: (http://upd-tl.com/upd. html).

The CNVs were classified according to the American College of Medical Genetics (ACMG) definitions [37]: pathogenic, benign, and variants of uncertain significance (VOUS) which can be further classified as likely pathogenic, likely benign, and CNVs of little or no relevant clinical information. Parental blood samples were collected and analyzed by CMA to provide more information if the aberration was determined to be potentially clinically significant.

\section{Conventional karyotyping}

Conventional karyotyping consisted of cell culture and G-banded karyotyping was performed according to the standard protocols in our laboratory at the 320-500 bands level. The karyotype was determined according to the International System for Human Cytogenetic 2016 (ISCN 2016).

\section{Clinical follow-up}

For all fetuses diagnosed with VOUS, likely pathogenic or pathogenic variants, parental DNA testing by SNP array was offered to define parental origin in order to further interpret the pathogenicity of fetal CNVs. The long-term follow-up was performed with a median infant age of 11 months through the patient's medical record or telephone inquiry.

\section{Abbreviations}

AMA: Advanced maternal age; CMA: Chromosomal microarray analysis; CNVs: Copy number variants; FGR: Fetal growth restriction; iUPD: Isodisomic uniparental disomy; LCRs: Low copy repeats; LOH: Loss of heterozygosity; TOP: Termination of the pregnancy; UPD: Uniparental disomy;

VSD: Ventricular septal defect

\section{Acknowledgements}

The authors want to thank Min Zhang and Yan Wang for their technical support on SNP analysis. The authors thank Gang An for analyzing and interpreting the array data.

\section{Authors' contributions}

$X W$ and LX prepared the main manuscript; XX, MC, LS, prepared the experiment. All authors have read and approved the final article.

\section{Funding}

The present study was supported by The Fujian Provincial Natural Science Foundation (Grant No. 2017 J01238).

Availability of data and materials

The datasets used and/or analyzed during the current study are available from the corresponding author on reasonable request.

Ethics approval and consent to participate

The present study was approved by the Protection of Human Ethics Committee of Fujian Provincial Maternity and Children's Hospital, affiliated hospital of Fujian Medical University (NO.1001). Written informed consent for participation was received for all patients.

\section{Consent for publication}

All patients have provided written informed consent prior to participating in the present study.

\section{Competing interests}

The authors declare that they have no competing interests.

Received: 5 June 2019 Accepted: 10 July 2019

Published online: 05 August 2019

\section{References}

1. Du Y, Chen L, Lin J, Zhu J, Zhang N, Qiu X, et al. Chromosomal karyotype in chorionic villi of recurrent spontaneous abortion patients. Biosci Trends. 2018;12(1):32-9. 
2. Joel M, Cliff H, Gordon LA, Astrid T, Shyam P, Xinwei S, et al. The sequence and analysis of duplication-rich human chromosome 16 Nature. 2004;432(7020):988.

3. Eichler EE, Johnson ME, Alkan C, Tuzun E, Sahinalp C, Misceo D, et al. Divergent origins and concerted expansion of two segmental duplications on chromosome 16. J Hered. 2001;92(6):462-8.

4. Wang J, Chen L, Zhou C, Wang L, Xie H, Xiao Y, et al. Prospective chromosome analysis of 3429 amniocentesis samples in China using copy number variation sequencing. Am J Obstet Gynecol. 2018;219(3):287.e1-e18.

5. Wang JC, Radcliff J, Coe SJ, Mahon LW. Effects of platforms, size filter cutoffs, and targeted regions of cytogenomic microarray on detection of copy number variants and uniparental disomy in prenatal diagnosis: results from 5026 pregnancies. Prenat Diagn. 2019;39(3):137-56.

6. Mefford HC, Muhle H, Ostertag P, von Spiczak S, Buysse K, Baker C, et al. Genome-wide copy number variation in epilepsy: novel susceptibility loci in idiopathic generalized and focal epilepsies. PLoS Genet. 2010;6(5):e1000962.

7. Ramalingam A, Zhou XG, Fiedler SD, Brawner SJ, Joyce JM, Liu HY, et al. $16 p 13.11$ duplication is a risk factor for a wide spectrum of neuropsychiatric disorders. J Hum Genet. 2011;56(7):541-4.

8. Martin J, Han C, Gordon LA, Terry A, Prabhakar S, She X, et al. The sequence and analysis of duplication-rich human chromosome 16. Nature. 2004; 432(7020):988-94.

9. Cox DM, Butler MG. The 15q11.2 BP1-BP2 microdeletion syndrome: a review. Int J Mol Sci. 2015;16(2):4068-82.

10. Cheng SSW, Chan KYK, Leung KKP, PKC A, Tam WK, SKM L, et al. Experience of chromosomal microarray applied in prenatal and postnatal settings in Hong Kong. Am J Med Genet C Semin Med Genet. 2019;181(2):196-207.

11. Allach El Khattabi L, Heide S, Caberg JH, Andrieux J, Doco Fenzy M, Vincent-Delorme C, et al. 16p13.11 microduplication in 45 new patients: refined clinical significance and genotype-phenotype correlations. J Med Genet. 2018;0:1-7.

12. Bakircioglu M, Carvalho OP, Khurshid M, Cox JJ, Tuysuz B, Barak T, et al. The essential role of centrosomal NDE1 in human cerebral cortex neurogenesis. Am J Hum Genet. 2011:88(5):523-35.

13. Hannes FD, Sharp AJ, Mefford HC, de Ravel T, Ruivenkamp CA, Breuning $\mathrm{MH}$, et al. Recurrent reciprocal deletions and duplications of 16p13.11: the deletion is a risk factor for MR/MCA while the duplication may be a rare benign variant. J Med Genet. 2009;46(4):223-32.

14. de Kovel CG, Trucks H, Helbig I, Mefford HC, Baker C, Leu C, et al. Recurrent microdeletions at 15q11.2 and 16p13.11 predispose to idiopathic generalized epilepsies. Brain. 2010;133(Pt 1):23-32.

15. Heinzen EL, Radtke RA, Urban TJ, Cavalleri GL, Depondt C, Need AC, et al. Rare deletions at 16p13.11 predispose to a diverse spectrum of sporadic epilepsy syndromes. Am J Hum Genet. 2010;86(5):707-18.

16. Ullmann R, Turner G, Kirchhoff M, Chen W, Tonge B, Rosenberg C, et al. Array CGH identifies reciprocal 16p13.1 duplications and deletions that predispose to autism and/or mental retardation. Hum Mutat. 2007;28(7):674-82.

17. Ingason A, Rujescu D, Cichon S, Sigurdsson E, Sigmundsson T, Pietilainen OP, et al. Copy number variations of chromosome 16p13.1 region associated with schizophrenia. Mol Psychiatry. 2011;16(1):17-25.

18. Kirov G, Rees E, Walters JT, Escott-Price V, Georgieva L, Richards AL, et al. The penetrance of copy number variations for schizophrenia and developmental delay. Biol Psychiatry. 2014;75(5):378-85.

19. Weiss LA, Yiping S, Korn JM, Dan E, Arking MDT, Ragnheidur F, et al. Association between microdeletion and microduplication at 16p11.2 and autism. N Engl J Med. 2008;358(7):667.

20. Kumar RA, Samer KM, Jyotsna S, Conrad DF, Camille B, Badner JA, et al. Recurrent 16p11.2 microdeletions in autism. Hum Mol Genet. 2008; 17(4):628-38

21. Marshall CR, Noor A, Vincent JB, Lionel AC, Feuk L, Skaug J, et al. Structural variation of chromosomes in autism Spectrum disorder. Am J Hum Genet. 2008;82(2):477-88.

22. Dell'Edera D, Dilucca C, Allegretti A, Simone F, Lupo MG, Liccese C, et al. 16p11.2 microdeletion syndrome: a case report. J Med Case Rep. 2018;12(1):90.

23. Ghebranious N, Giampietro PF, Wesbrook FP, Rezkalla SH. A novel microdeletion at 16p11.2 harbors candidate genes for aortic valve development, seizure disorder, and mild mental retardation. Am J Med Genet A. 2010:143A(13):1462-71.
24. Bijlsmaa EK, Schuurs-Hoeijmakers JHM, Haeringen AV, van de Putte DE F, Anderlid BM, Lundin J, et al. Extending the phenotype of recurrent rearrangements of $16 p 11.2$ : deletions in mentally retarded patients without autism and in normal individuals. Eur J Med Genet. 2009;52(2):77-87.

25. Čiuladaite Ž, Kasnauskienè J, Cimbalistienè L, Preikšaitienè E, Patsalis PC, Kučinskas V. Mental retardation and autism associated with recurrent $16 p 11$. 2 microdeletion: incomplete penetrance and variable expressivity. J Appl Genet. 2011;52(4):443-9.

26. Shimojima K, Inoue T, Fujii Y, Ohno K, Yamamoto T. A familial 593-kb microdeletion of 16 p11.2 associated with mental retardation and hemivertebrae. Eur J Med Genet. 2009:52(6):433-5.

27. Lin S, Shi S, Zhou Y, Ji Y, Huang P, Wu J, et al. Intrauterine phenotypic features associated with 16p11.2 recurrent microdeletions. Prenat Diagn. 2018;38(6):381-9.

28. Fei Q, Wu Z, Wang H, Zhou X, Wang N, Ding Y, et al. The association analysis of TBX6 polymorphism with susceptibility to congenital scoliosis in a Chinese Han population. Spine. 2010;35(9):983-8.

29. Ballif BC, Hornor SA, Jenkins E, Madan-Khetarpal S, Surti U, Jackson KE, et al. Discovery of a previously unrecognized microdeletion syndrome of $16 \mathrm{p} 11$. 2-p12.2. Nat Genet. 2007;39(9):1071-3.

30. Hempel M, Rivera Brugues N, Wagenstaller J, Lederer G, Weitensteiner A,

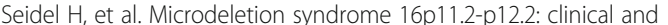
molecular characterization. Am J Med Genet A. 2009;149A(10):2106-12.

31. Bicknell LS, Bongers EM, Leitch A, Brown S, Schoots J, Harley ME, et al. Mutations in the pre-replication complex cause Meier-Gorlin syndrome. Nat Genet. 2011:43(4):356-9.

32. Kranz C, Denecke J, Lehle L, Sohlbach K, Jeske S, Meinhardt F, et al. Congenital disorder of glycosylation type Ik (CDG-Ik): a defect of mannosyltransferase I. Am J Hum Genet. 2004;74(3):545-51.

33. Nakabayashi K, Trujillo AM, Tayama C, Camprubi C, Yoshida W, Lapunzina $P$, et al. Methylation screening of reciprocal genome-wide UPDs identifies novel human-specific imprinted genes. Hum Mol Genet. 2011;20(16):3188-97.

34. Barbaux S, Gascoin-Lachambre G, Buffat C, Monnier P, Mondon F, Tonanny $\mathrm{MB}$, et al. A genome-wide approach reveals novel imprinted genes expressed in the human placenta. Epigenetics. 2012;7(9):1079-90.

35. Choufani S, Shapiro JS, Susiarjo M, Butcher DT, Grafodatskaya D, Lou Y, et al. A novel approach identifies new differentially methylated regions (DMRs) associated with imprinted genes. Genome Res. 2011;21(3):465-76.

36. Girirajan S, Rosenfeld JA, Coe BP, Parikh S, Friedman N, Goldstein A, et al. Phenotypic heterogeneity of genomic disorders and rare copy-number variants. N Engl J Med. 2012;367(14):1321-31.

37. South ST, Lee C, Lamb AN, Higgins AW, Kearney HM. Working Group for the American College of medical G, et al. ACMG standards and guidelines for constitutional cytogenomic microarray analysis, including postnatal and prenatal applications: revision 2013. Genet Med. 2013;15(11):901-9.

\section{Publisher's Note}

Springer Nature remains neutral with regard to jurisdictional claims in published maps and institutional affiliations.

Ready to submit your research? Choose BMC and benefit from:

- fast, convenient online submission

- thorough peer review by experienced researchers in your field

- rapid publication on acceptance

- support for research data, including large and complex data types

- gold Open Access which fosters wider collaboration and increased citations

- maximum visibility for your research: over $100 \mathrm{M}$ website views per year

At $\mathrm{BMC}$, research is always in progress.

Learn more biomedcentral.com/submissions 